\title{
Avian Influenza A Virus
}

National Cancer Institute

\section{Source}

National Cancer Institute. Avian Influenza A Virus. NCI Thesaurus. Code C53496.

A subtype of type A influenza virus found chiefly in birds, but infections with these viruses can occur in humans. 